Article

\title{
Organisational Identity as a Barrier to Widening Access in Scottish Universities
}

\author{
Vikki Boliver*(D), Mandy Powell ${ }^{\mathbb{D}}$ and Tiago Moreira \\ Department of Sociology, Durham University, 32 Old Elvet, Durham DH1 3HP, UK; \\ mandy.powell@durham.ac.uk (M.P.); tiago.moreira@durham.ac.uk (T.M.) \\ * Correspondence vikki.boliver@durham.ac.uk
}

Received: 29 July 2018; Accepted: 4 September 2018; Published: 6 September 2018

\begin{abstract}
Widening access policy has historically focused on tackling the socioeconomic barriers to university access faced by prospective students from under-represented groups, but increasingly policy makers are seeking to also address the barriers to wider access posed by undergraduate admissions policies. In this vein, the Scottish Government has recently called upon universities to set separate academic entry requirements for socioeconomically disadvantaged applicants which recognise that "the school attainment of disadvantaged learners often does not reflect their full potential" and which better reflect the minimum needed to succeed in higher education. In this paper, we draw on in-depth interviews with admissions personnel at eighteen Scottish universities to explore the scope for more progressive admissions policies of this kind in light of universities' identities as organisations and in light of corresponding organisational strategies for position-taking in global and national higher education fields. We present a theoretical model and an empirical illustration of three hierarchically-ordered ideal types of organisational identity-globally competitive, nationally selective, and locally transformative-and show that the more dominant of these tend to constrain the development of more progressive admissions policies. This is because globally competitive and, to a lesser extent, nationally selective organisational identities are understood to require admission of the 'brightest and best', conceptualised as those with the highest levels of prior academic attainment who can be expected to succeed at university and beyond as a matter of course. We conclude that universities must recognise and redress the implicitly exclusionary nature of their organisational identities if genuine progress on widening access is to be made.
\end{abstract}

Keywords: admissions practices; contextualised admissions; fair access; field; position-taking; structural disadvantage; Bourdieu

\section{Introduction}

Young people living in Scotland's most affluent neighbourhoods are around three and a half times more likely to enter undergraduate university courses than their peers from Scotland's most deprived communities (UCAS 2017), and are nearly five times as likely to enter a highly academically selective institution according to the last statistics to be released (UCAS 2015). A major reason for this disparity is the corresponding disparity in school attainment, with young people from disadvantaged backgrounds much less likely than their more advantaged counterparts to be eligible for higher education (Commission on Widening Access 2015) and much less likely to achieve the high grades stipulated by the most academically selective universities (Boliver et al. 2017). Widening access initiatives have typically focused on tackling this and other barriers to undergraduate university access rooted in the socioeconomic disadvantages faced by those from groups under-represented in higher education. Such initiatives have met with only limited success, however, with progress on widening access moving at a slow pace over the last decade, such that the socioeconomic gap in university 
participation rates remains higher in Scotland than in England, due partly to a greater preponderance of highly academic selective universities in the Scottish context (Blackburn et al. 2016).

Recently, there has been growing recognition among policy makers that the barrier to widening access caused by socioeconomic disparities in school attainment is exacerbated by the admissions policies of universities. The Scottish Government's Commission on Widening Access (CoWA) noted in its interim report that, over the course of the past decade, higher education institutions have substantially increased their undergraduate academic entry requirements as a means of reducing overly burdensome levels of applicant demand (Commission on Widening Access 2015). As a result, many bachelor degree programmes now require students to demonstrate levels of prior academic performance that far exceed the pedagogically necessary minimum and which are further beyond the reach of many prospective students from disadvantaged backgrounds than before. This phenomenon is not unique to Scotland, having been documented also in England (Boliver et al. 2017), and in the United States where disadvantaged ethnic minorities have been disproportionately excluded as a result of rising SAT test score requirements (Posselt et al. 2012). In light of this, in its final report CoWA recommended that:

“By 2019 all universities should set access thresholds for all degree programmes against which learners from the most deprived backgrounds should be assessed. These access thresholds should be separate to standard entrance requirements and set as ambitiously as possible, at a level which accurately reflects the minimum academic standard and subject knowledge necessary to successfully complete a degree programme." (Commission on Widening Access 2016, p. 11)

CoWA's recommendation is that Scottish universities engage in a strong form of what has become known in the UK as "contextualised admissions" (Schwartz 2004). As the CoWA reports acknowledge, many Scottish universities already operate some form of contextualised admissions and some have been doing so for some time (Cree et al. 2006; Croxford et al. 2014). However, not all universities routinely reduce academic entry requirements for disadvantaged applicants—instead giving such applicants additional consideration for a university place subject to standard academic entry requirements - and where entry requirements are reduced this is typically by just one or two grades (Boliver et al. 2017). The CoWA recommendation thus calls on universities to take "more radical action" than ever before, by reducing entry requirements for disadvantaged students across the board, and doing so by as many grades as possible (Commission on Widening Access 2016, p. 37).

It is clear that CoWA regards the development of more progressive admissions policies as key to meeting the Scottish Government's ambition that "a child born today in one of our most deprived communities should have no lesser chance of entering higher education than a child born in one of our least deprived [communities]" (Scottish Government 2014). The target set by CoWA for the sector as a whole is to increase the representation of those from Scotland's $20 \%$ most deprived neighbourhoods (as measured by the Scottish Index of Multiple Deprivation, and referred to as SIMD20) to at least $16 \%$ of entrants to full-time bachelor degree programmes by 2021 , rising to at least $18 \%$ by 2026 , and $20 \%$ by 2030 . In recognition of the already uneven distribution of disadvantaged students across the sector, targets have also been set to increase the representation of those from the $20 \%$ most deprived neighbourhoods to at least 10\% of entrants to every university in Scotland by 2021, with higher institution-specific targets to follow. Although SIMD20 and other area-level measures have been strongly critiqued for poor validity when it comes to identifying genuinely socioeconomically disadvantaged individuals (Boliver et al. 2017; Gorard et al. 2017), it remains the Scottish Government's preferred measure at present. Even so, according to the latest figures available, only two of Scotland's nineteen universities meet the $20 \%$ target, and eight have yet to reach even the $10 \%$ mark (SFC 2018).

The representative body for Scottish universities has responded to CoWA's access thresholds recommendation and associated targets in a broadly positive manner (Universities Scotland 2017). However, it remains to be seen how much further universities are prepared to go, individually and collectively, to reduce the admissions hurdle for disadvantaged applicants. In this paper we explore the 
scope for progressive admissions policies of the kind exemplified by the CoWA recommendation. We focus, in particular, on the critical and potentially limiting influence of organisational identity and of associated organisational strategies for position-taking in global and national higher education fields.

The concept of organisational identity refers to the set of attributes invoked by an organisation to define itself and to distinguish it from other organisations (Albert and Whetten 1985), and as such represents a useful conceptual tool for exploring how universities perceive and convey their central character and purpose, including that of their admissions function. The self-defined central, enduring and distinguishing attributes of an organisation represent claims regarding the core and longstanding characteristics of the organisation which mark it out as both distinctive, in the sense of different, and distinguished, in the sense of worthy of esteem (Whetten 2006). These identity claims entail references to the "unique pattern of binding commitments" of the organisation which signify the "unique social space" it occupies (Whetten 2006, p. 220).

A critical feature of organisational identity is that it functions as a categorical imperative, informing and circumscribing what is perceived to be appropriate action "for an organisation like us" (Whetten 2006, p. 223). As such, organisational identity may represent a barrier to the adoption of more progressive admissions policies if these are perceived to conflict with current conceptions of "who we are as an organisation" (Puusa et al. 2013) or with future-oriented strategic claims about "what our ambitions are for the future" (Stensaker 2015). Current conceptions of "who we are" are typically couched in essentialist terms, as intrinsic and immutable features of the organisation, which tend to serve as a significant barrier to change. As Whetten notes:

"higher level organisational attributes, including adopted social forms and organising logics can be considered structural analogues of "inherent" individual attributes such as gender and ethnicity, on the grounds that the perceived switching costs associated with the replacement of these core identifying features are so high that the prospect of doing so is, practically speaking, unthinkable". (Whetten 2006, p. 226)

The future-oriented component of organisational identity, on the other hand, suggests that identities are fluid and open to change (MacDonald 2013, p. 161). However, in practice the identity aspirations of universities have been observed to revolve around a desire to emulate the attributes of other, more esteemed, organisations, leading to a degree of isomorphism over time (Labianca et al. 2001; Brankovic 2018). All universities are engaged in organisational identity processes and practices but the dominant model of the research-intensive, 'world-class' university is setting the rules of the game and determining the direction of travel (Hazelkorn 2007; David 2016).

Organisational identity claims, then, are not only comparative acts but also fundamentally competitive ones (MacDonald 2013, p. 158), involving the staking of a claim to a particular position in a hierarchically ordered 'field' (Bourdieu 1996), and a statement of intent to maintain or improve positional advantage in that field in the future. Historically, higher education fields have been local and national ones (Naidoo 2004; Mateos-González and Boliver forthcoming), but increasingly universities are also positioned in relation to other universities worldwide in a global higher education field (Marginson 2006, 2008). Positional advantage in the global higher education field tends to be valorised over positional advantage in the national field, which in turn tends to be valorised over position in the local field, partly because of the greater degree of organisational autonomy it requires and implies (Bourdieu 1993). Universities will therefore tend to express their organisational identity with reference to the highest level of field to which they can credibly claim positional advantage.

Given the centrality of research and of teaching to the definition of "a university", these functions can also be expected to be central components of the organisational identities of all universities. Specific universities will vary, however, with regard to the primacy accorded to research versus teaching (Boliver 2015, p. 613). Distinction in research tends to be valued over distinction in teaching, partly because the former is regarded as an autonomous endeavour whereas the latter is seen as more heteronomously determined by the dictates of the State and the vicissitudes of the undergraduate 
market. Consequently, if a university can credibly lay claim to a high degree of distinction in research, its organisational identity is likely to be framed principally by the primacy of research over teaching.

Different organisational identities can also be expected to manifest in different framings of the teaching function of universities. Universities in high demand by students and by graduate employers are likely to emphasise the highly academically competitive nature of admission to their taught programmes, with this competitiveness in and of itself taken to speak to the high quality of the organisation's teaching processes and outputs (Marginson 2006). Competitive admission is valorised because it signifies a high degree of organisational autonomy regarding who, what and how the university teaches, with the implication that there is no need for scrutiny of the teaching and learning process so long as demand for undergraduate places far outstrips supply. The taught provision of universities which actively recruit their students, in contrast, is more heteronomously determined by the needs of students and graduate employers, and so claims to distinction will tend to emphasise support for learning and the acquisition of knowledge and skills valued in the workplace.

Drawing on this elaboration of the concept of university organisational identity, and on data drawn from a large number of in-depth interviews with admissions personnel in Scottish universities, we identify three distinctive forms of organisational identity and explore how each of these shapes and constrains orientations to admissions. Section 2 describes the data on which this paper is based and summarises our approach to its analysis. Section 3 presents our empirical findings which culminate in the key insight of our work: that the organisational identities of universities tend to exert a curtailing influence on the adoption of more progressive approaches to admissions because admitting students with grades substantially below the 'market rate' is regarded by many universities as incompatible with "who we are as an organisation" (Puusa et al. 2013), or else with "what our ambitions are for the future" (Stensaker 2015). In our Section 4, we discuss the implications of this key insight for the viability of more progressive admissions policies in Scotland and elsewhere.

\section{Data and Methods}

This article draws on primary data collected from almost the whole population of universities in Scotland $(\mathrm{n}=18)^{1}$ using in-depth semi-structured interviews $(\mathrm{n}=75)$ with admissions personnel ( $\mathrm{n}=97$ ) supplemented by publicly available institutionally-authored policy documents including admissions policies and strategic plans. Interviews were conducted to scope admissions processes $(n=19)$ and to discuss the work of admissions policy-makers $(n=14)$, selectors $(n=23)$, data managers $(n=8)$, outreach staff $(n=7)$, student support staff $(n=1)$ and staff with other responsibilities $(n=2)$. The purpose of the interviews was to gain insight into organisational orientations to admissions, selection, widening access and contextualised admissions policies and practices from the perspective of university personnel engaged in a range of admissions-related roles. These data were collected during the 2015/16 academic year as part of larger mixed methods project funded by the Scottish Funding Council which set out to map and evaluate the use of contextual data as a widening access tool in Scottish universities (Boliver et al. 2017).

Policies and practices in each institution were examined using a case study methodology, allowing a detailed and in-depth engagement with each institution as a unique case. Case studies are typically associated with the study of a single case or small sub-set of cases to shed light on the dimensions of a wider social phenomenon of interest (Yin 2009) but may not adequately represent the wider population of cases. This research, however, includes multiple cases from almost the entire population of Scottish

1 Specifically, the research included the universities of Aberdeen, Abertay Dundee, Dundee, Edinburgh, Edinburgh Napier, Glasgow, Glasgow Caledonian, Heriot-Watt, Highlands and Islands, Queen Margaret, Robert Gordon, St Andrews, Stirling, Strathclyde, and West of Scotland; and three specialist-discipline higher education institutions, Glasgow School of Art, Royal Conservatoire Scotland, and Scotland's Rural College. The project did not include the Open University in Scotland, which has a unique open admissions policy, nor the large number of Scottish further education colleges offering higher education programmes. 
higher education institutions. The aim of this paper is to present a synthesis of the findings from individual cases by systematically comparing across cases to throw light on dimensions relevant to the whole population of cases under analysis (Ragin 2014).

The data were analysed using thematic coding and constant comparison to build new categories based on the different perspectives and views shared via interview. These techniques were used iteratively to establish a coding frame in team data clinics. Systematic coding of the interviews led to the formulation of ideal types to construct "unified analytical constructs" (Weber 1949, p. 147). The resulting ideal types do not correspond to any specific case but are ideal in the sense of being a logical synthesis of characteristics found empirically in the cases. Used as a heuristic, the inductive construction of ideal types from the interview data enabled us to develop a typology of organisational identities and associated approaches to admissions.

\section{Results}

Our analysis of data for the Scottish university sector suggested three hierarchically-ordered ideal types of university organisational identity, each associated with different orientations to undergraduate admissions.

In summary, the first and most prestigious of these types of organisational identity-that of the globally competitive university [identified by GC in the interview quotations below] - emphasises a reputation for world-class research and a high level of demand for undergraduate places not only nationally but also globally. Correspondingly, the globally competitive university prides itself on admitting the 'brightest and best' students from a large pool of highly qualified applicants who, by virtue of their manifest academic ability, coupled with access to the organisation's world-class facilities, can be expected to succeed educationally as a matter of course. The globally competitive university's ambition for the future centres on maintaining and improving its position in the global higher education field.

The second type of organisational identity found in our data-that of the nationally selective university [NS] — distinguishes itself by reference to nationally recognised excellence in research and teaching, together with a high level of demand for undergraduate places nationally. The nationally selective university draws distinction from admitting applicants with high (but not necessarily the very highest) levels of prior achievement, and from teaching practices that support learning in a light touch manner. Often, organisations identifying as a nationally selective university aspire to become globally competitive ones either in specific disciplinary specialisms or across the board.

The third form of organisational identity-the locally transformative university [LT] — distinguishes itself by claims to excellence in teaching and learning rather than research, and makes a virtue of its commitment to providing highly supportive personalised learning aimed at moderate-to-low attaining students living within the local region who might not otherwise be able to access higher education. Teaching is framed as designed to equip such students with the knowledge and skills sought by local graduate employers. Some locally transformative universities harbour aspirations to become nationally selective in core disciplinary specialisms.

Below we discuss in more detail how these three forms of organisational identity shape orientations to university admissions. We focus first on how universities identifying or aspiring to identify as globally competitive, or to a lesser extent as nationally selective, regard academic selectivity in undergraduate admissions as central to their claim to distinction in the field. We then show how this privileging of academic selectivity in admissions makes it difficult for these universities to envisage how strongly progressive admissions policies might be reconciled with 'who we are' or else 'what our ambitions are for the future'. Finally, we show that the apparent irreconcilability of strongly progressive admissions policies with more 'elite' forms of organisational identity are linked to a particular understanding of the teaching function of the university: as entailing the transmission of knowledge to those who are already well-placed to assimilate it, rather than as a process of supporting students to learn. 


\subsection{Organisational Identity and Academic Selectivity in Admissions}

Most of the universities in our data were engaged in academically selective admissions to some degree. However, our interviewees at globally competitive universities saw the primary goal of the admissions process as being to admit those with the very highest qualifications:

"We start off at the beginning of the cycle with an idea of who we are going to make early offers to ... and we make early offers to those who have achieved particular criteria that we will have worked out based on how things went in previous years. So for example, in a particular programme, they [faculty staff] may say "we make offers to all those who have already achieved straight As to include these [essential] subjects'." [GC]

This focus on admitting those with the highest grades was rooted in the view that it was 'known' that high grades are a prerequisite of student success at a globally competitive university:

"I'm not here to be fair to an individual, and I think that's the understanding that people get, is this fairness to an individual. If the other guys come at me and say you're not being access friendly we can say well actually, we know we require these grades to do well" [GC]

"Where access comes in I would say if it's got ... we do not make lower offers than what we think the minimum is. We stand by what we think the minimum you require to do well here" [GC]

A related justification was that it was 'known' that the intellectual sophistication of students attending the institution is something that is valued by employers of globally competitive university graduates:

"evidence shows that the intellectual and personal maturity and flexibility that we value in graduates from this system are also highly prized by employers" [GC]

For nationally selective universities, grades were also the primary consideration when making admission decisions, with lower performing students potentially making the cut at the end of the admissions cycle if places remain:

"[the] student's overall profile determines which round they sit in ... so broadly, if it's 4Bs at Higher requirement and their overall profile is $4 \mathrm{Bs}$ they're in round three. If they've got $1 \mathrm{~A}$ and 3Bs they're be in round two and if they've got 2As and 2Bs they're two grades above the minimum entry criteria and they'll be in round one. So round one will be processed first, then round two, then round three. Round four, they won't be rejected, but they'll sit in round four and we look at that, and then maybe, if there are places available, they may receive offers for round four" [NS]

As with globally competitive universities, for nationally selective universities high applicant demand meant that they could easily fill all of their places with highly qualified applicants, mostly from advantaged backgrounds:

"So, very high demand and that means that essentially if you leave aside any widening access considerations, we operate a gathered field, you'd be making say 300 unconditional offers to students that have $4 \mathrm{As}$ and $1 \mathrm{~B}$ or $5 \mathrm{As}$ " [NS]

Entry requirements at nationally selective universities were typically lower than for globally competitive universities, but still high by national standards, and there was a clear perception that top grades are needed in at least some examination subjects:

"The grades are lower so we can give opportunities to students who haven't performed at the $4 \mathrm{As}$ and 1B, 5As level at school. And not every department in the faculty needs $4 \mathrm{As}$ and a B, but certainly you'd need As in [at least two subjects] to be considered for most courses" [NS] 
Some nationally selective universities are relatively recent entrants to the national higher education field, and fully recognise the positive reputational implications of selecting rather than recruiting applicants onto their programmes:

"It's really only been in the last four or five years that reputationally and everything else in terms of undergraduates that [the university has] moved in to a position where it would be more selective about the students that it takes in" [NS]

There was also recognition within nationally selective universities that emulating the very high academic entry requirements associated with globally competitive universities might be considered desirable in terms of positioning in the field. However, realism about current identity and position in the field had a braking effect on these ambitions, preventing entry requirements from being raised higher than their current core market could bear.

"Now everybody in some ways would like to be an institution that only accepts 5As because we're so fantastic. That's not us. And sometimes people, depending on who it is, I don't actually have to do it very often, that's just something I've recently said so let's be careful here, we do have a widening access agenda, we do have a contextualised admissions policy, we don't want to be pricing ourselves out of that market, we want to keep those statistics up, we want to be that type of institution so do we really need to be asking for $3 \mathrm{As}$ and $2 \mathrm{Bs}$ on that programme where traditionally we've taken $1 \mathrm{~A}$ and $4 \mathrm{Bs}^{\prime \prime}$ [NS]

Although locally transformative universities generally recruited, rather than selected, their students, some of their programmes, typically those leading to professional occupations, were in high demand, and for these programmes grades were the key selection criteria:

"If it's a very competitive programme and we go through gathered field, we hold everything back and it's processed as a batch and it's priority one, priority two, priority three in terms of the competitive nature ... if someone has got maybe 4Bs and some's got 3Bs, some's got 2Bs, we're looking at them in terms, the most competitive ones, in terms of having the highest qualifications per entry" [LT]

For some locally transformative universities, particular programmes have been in high-demand for some time, whereas for others this is a relatively recent development, which has prompted increases in entry requirements.

"Whereas we are probably getting towards a ... [higher position] ... in terms of ranking in Scotland ... there's a particular ... two courses had a very, very unreasonably high outcome per place ratio, and it was felt that it could still more than comfortably fill the places [after increasing entry requirements] and would be more appropriate because ultimately those students who were presenting much lower [levels of attainment], they were wasting a choice. They were never going to be at the top end of the sift, if you like, so it was seen as more realistic to cut down those number of applications" [LT]

For some staff in locally transformative universities, rising entry requirements were seen in a positive light, as evidence that the university was moving up into the national higher education field:

“... it's seen I think, by and large, as a positive step if where, as an institution, we can raise entry requirements we will if we can still maintain a good number of applications and interest per place ... it's not an institutional objective to raise them where we can. There isn't really any high level strategy forcing that. It's more that where there are hundreds of applications ... out of step slightly with what other institutions are asking" [LT]

However, others in locally transformative universities were keenly aware that becoming part of the national higher education field would potentially come at a cost to widening participation: 
"we weren't a selecting university we were a recruiting university and that's changed because we no longer go into clearing [to fill places at the end of the admissions cycle]. So it changes and what we've done is we've upped our criteria for entry and ... that then has an impact on your other transitions in [i.e., admittances of prospective students from disadvantaged backgrounds]. So the areas that will be less advantaged coming in. It's a difficulty because you push towards the academic excellence, which the university wants to have, but how do you manage that with the transitions?" [LT]

"but that [entry requirements] has gone up over the last few years and this year we've put up ... but in doing that I feel that we've introduced contextual [admissions] so for me that's a kind of a ... because I think one of the reasons I've been disinclined to put grades up is my concern that you're missing people who really should be getting an offer from us ... we've got to be careful here because you're getting a lot of great students who are coming in at [minimum entry grades] and we don't want to lose those" [LT]

Locally transformative universities reported that some staff within the institution were keen to see entry requirements increase across the board to enhance the esteem of the university. However, this view was not the mainstream view and was readily countered by reference to examples of students entering with modest grades but nonetheless performing to the highest standard at degree level:

"Just thinking about that I know that this does come across occasionally in meetings when staff say 'We should be upping our entry criteria' and it's really difficult to get across that actually just because somebody you know got a C instead of a B it doesn't mean that they are not capable students. And I think part of that is probably where most staff here, where they come from is probably universities who maybe did have those sorts of entry criteria. So there is this perception that unless you need three As, or five As in Scotland, to get into a university, your university is somehow devalued which I think is what you're saying, something about the students. I think what we do really well is take those students who perhaps are not straight A students but they absolutely can come out with fantastic degrees and they do" [LT]

\subsection{Organisational Identity as a Barrier to Progressive Admissions Policies}

For globally competitive universities, progressive admissions policies may be used to prioritise disadvantaged applicants for admission, but a strong preference remains for such applicants who have nevertheless managed to achieve the very high grades normally demanded by the institution:

"I'm going to go to [discipline] because I think we've got some [socioeconomically disadvantaged applicants] in there ... we've got some flags here, so I'm just going to see if I can find one with three [indicators of socioeconomic disadvantage] ... Oh there's one with three. So this one here looks like it's going to be an offer ... so that person is definitely who I know has got 3As, has definitely come from a diverse background, a low progression school and has definitely got some form of pre-engagement [with the university]. So we're talking about somebody there that we would really want to be interested in. So that's how it works. And then we make decisions on that." [GC]

Indicative of how central high academic entry requirements are to the identities of globally competitive universities, progressive admissions policies involving reduced entry requirements for disadvantaged applicants were sometimes seen to entail an unfair disadvantaging of highly qualified applicants from advantaged backgrounds:

"What we might do for an access [applicant], well we will do, if it's someone who is absolutely SIMD [i.e., from a deprived area], low progression [i.e., from a school with a low HE progression rate], they will be made an offer on the minimum [i.e., with reduced entry 
requirements]. Thus displacing someone who is not access who has got $5 \mathrm{As}$, so they've done ... and so there is a displacement issue here." [GC]

A corollary of this ambivalence about whether progressive admissions are unfair to advantaged students is that globally competitive, and to a lesser extent nationally selective, universities displayed a reluctance to set out such policies in a highly public manner:

"we don't actually set out anywhere that says it's ABB but if you come from this postcode it will be [lower] ... you know ... because it's very difficult and the tension is there about what you would actually say and what's reasonable to say" [GC]

Nationally selective universities were typically cognisant of this 'displacement' concern too, and were mindful of the need to counter this view with the argument that comparable grades do not necessarily imply equal effort:

"A lot of the time when you encounter people who are resistant to widening access it doesn't mean that they're an ogre. A lot of the time they are just thinking well hang on a minute, if we have a finite amount of places and people work hard to get here, the kids work really hard to get their grades, so why should we penalise people who are getting the better grades. So I think it is really important to say right, well that's a valid concern, but what we're seeing is that a B at Higher Maths and a B at Higher Maths do not always mean the same amount of effort" [NS]

Our interviewees at both globally competitive and nationally selective universities frequently acknowledged that socioeconomic disparities in school achievement stem from structural inequality in the wider society, but only when offering interpretations of anomalous instances in which socioeconomically disadvantaged applicants had achieved high grades despite the odds. However, the logical counterpoint to this-that, because of structural inequality, most socioeconomically disadvantaged students do not achieve high grades—was rarely acknowledged explicitly.

Indeed, both globally competitive universities and nationally selective ones frequently spoke about the particular kind of widening access applicant who would especially pique their interest: someone who had evidently experienced a great deal of socioeconomic adversity but had overcome this, almost heroically, by nevertheless achieving the very high grades normally expected by the institution:

"those who have come through the adversity of some core kind and still perform to the level that we want" [GC]

"and they are living in a residential unit at the moment which is not anywhere that's going to be conducive to you getting good grades in sixth year. They'd done well in fifth year as well. Not well enough to get this S6 tariff but again we made a decision to make that conditional offer to this person because it will encourage them to get through the fact they're living in a residential until with people that they're basically taking drugs and drunk all the time, uninterested in studying" [GC]

"My goodness, they've got all of that and they came from that school. Goodness, that's a really strong potential" [NS]

Where entry requirements were relaxed by globally competitive universities, this was often (with some exceptions) by just one or two grades. The rationale for making only minor adjustments was underpinned by in-house research which indicated that academic performance levels would be comparable to those admitted on the basis of standard entry criteria:

"So what we did with that data was actually talked to our admissions colleagues and those with high entrance exam, typical entry were things such as 4 As, they then reduced that to 4 As and a B, but it is in order to gather that group of young people who would perform just as well." [GC] 
"what our research shows though is that ... if somebody comes from a widening access background and they come to the university and we admit them on an adjusted tariff ... If we do that we know that they will perform as well as a person who's been admitted on the standard" [GC]

Where reduced entry requirements were used by globally competitive universities, the overarching aim of admitting the highest performing students remained, and relatively high minimum grade requirements were used to 'deter' those considered insufficiently academically able from applying in the first place:

"how best do we express this, is it a range, is it that [there is a] standard [and a] minimum [set of academic entry requirements] ... to try to be transparent and attract the students we particularly want to attract who were academically able from whatever backgrounds and those from WP backgrounds particularly but how we deter those who just aren't going to be in with a shout because it's not fair on them and it's a huge burden for us potentially" [GC]

Globally competitive universities also typically required the beneficiaries of more progressive admissions policies to demonstrate their suitability for admission by successfully completing bespoke pre-entry programmes, as did many nationally selective universities:

"the tariffs have increased about the last three years ago, I think, the tariffs went up, which led to a decrease in MD40 applicants [i.e., applicants from the most deprived $40 \%$ of neighbourhoods], so we need more applicants from MD40 backgrounds because you've got a limited pool and what we're not doing is just making offers to people just because they're from a postcode ... we're going to ask them to come and do a programme as well" [GC]

"if they've convinced four academic colleagues independently over an intensive period [of engagement in a pre-entry programme] ... if four independent academics say they're ready, for me, who am I to say, or who is anyone to say they're not ready. So we've set up, if you like an alternative way of making sure that they're ready". [NS]

Some of our interviewees at nationally selective universities were mindful of the challenge to widening access presented by anticipated rises in applicant demand in the future, which would cement their position as nationally selective and potentially even globally competitive universities in the years to come. In some cases this prompted recognition of the need for an explicitly progressive element to admissions policies if disadvantaged students were not to be largely excluded:

"I expect that demand [for places] will to continue to grow, and therefore that pressure, and places will continue to be there. But that's precisely why things like contextual admissions for us is important to have as a way of managing that, balancing that demand ... curriculum changes and the attainment gap amongst the most deprived students will be a big challenge for us, you know." [NS]

While nationally selective universities also reported reducing entry requirements for disadvantaged students only modestly, so as not to compromise success rates, these universities were more likely than globally competitive ones to recognise that they may have a role to play in ensuring potential is realised:

"So now we started to bring in people on our contextual data and admissions policy we can look at what their attainment is going to be over first year, second year, third year and that will give us an indication of what to do next. I mean if they are performing just as well as their peers who've come with higher offers then we know that we're on the right track. If they're not, it doesn't mean that we've binned the contextual data policy, it means that we have to go and re-evaluate what's our student support that we offer" [NS] 
Locally transformative universities were much more likely to fully appreciate the structural roots of the socioeconomic gap in attainment. These universities recognised the potential in those whose achievement levels were low in comparison to the national average but strong relative to those from similar backgrounds:

"But it would always be a lesser academic offer ... so if we ask for a graded unit per se for a normal applicants we wouldn't ask for a graded unit for that group, so we try and make it a little bit easier for them to achieve what they have to achieve to get an entry ... we're there to kind of recognise that it is difficult for these applicants ... make it possible for these people to actually come to university" [LT]

That said, it was evident in relation to high demand programmes at locally transformative universities that more progressive admissions policies risked reducing rates of successful completion, thereby damaging the standing of the programme in national league tables:

"it's a professional qualification, we've always had particularly good progression and retention rates, they've always been amongst the best in the university but the general anxiety about performance and league tables means that we are under some pressure to not take a risk" [LT]

This aversion to taking a risk on less well qualified applicants was frequently voiced by transformative universities in relation to particular disciplinary specialisms that already held a place in the national, as opposed to local, field, or where the university had ambitions to play in the national field in the future.

\subsection{Organisational Identity and Orientations to Teaching and Learning}

Globally competitive universities often cited the 'traditional' nature of their teaching methods as a reason for being cautious about more progressive admissions policies:

"we have to be real that the people standing up and lecturing, the research interest that we have, the facilities that we use, the traditional methods ... we have quite a huge ratio of staff to students and we wouldn't want to stop that being a ... we want that to be a good student experience" [GC]

"and the difference of teaching style ... very traditional, very much about essays ... you need a type of student that will do that" [GC]

Usually implied but sometimes stated directly was the notion disadvantaged students with lower grades than the typical student at a globally competitive university might do well elsewhere, but not here:

"what university admissions have to be very careful about is that we do not take students in who might perform slightly less well in our institution because of our methods who could have performed exceptionally well in another university" [GC]

“It's not about who's better, who's worse, who's indifferent or whatever, it's about difference. And the difference of teaching style at [this university], which is very traditional, very much about essays before Christmas, modular exams, and all of those things. It produces ... you need a type of student that will do that and the type of student we felt that were benefitting from that were the ones who were attaining well in their Highers. Now that is not to say anybody with 2As and 3Bs who went to another university wouldn't get a first or a second. This is in this environment. So we felt that we had to contextualise not only the young person but also the institution" [GC] 
Globally competitive universities did occasionally acknowledge that the institution itself could play a role in helping disadvantaged students with lower-than-standard grades succeed at university, but this view was not often articulated:

"This is not about achieving a first class or a 2:1 whatever at the time of application. This is about a journey and enabling them to reach that potential. So if we are going to take students with a lower tariff they may need more support, particularly in first year to help stick with it and get through first year" [GC]

Nationally selective universities were more likely to voice this view:

"what's the point of making an adjustment [to the entry requirements] if you're not going to help the person to become a successful student, because they're going to come in and they're going to struggle. So you've got a far better chance of somebody being a good student if you work with them beforehand and work with them when they come in and there's all kinds of ways you can do it" [NS]

However, many nationally selective universities, whilst recognising the need for supported learning, saw this as a need that was yet to be fully met by the institution:

"I think a gap that we wouldn't acknowledge and need to look further at in the coming years is what happens next. Are we doing enough ... on our campus? Is it right that there would be some specific activity for them once they've matriculated because we don't currently treat them any differently?" [NS]

Locally transformative universities, in contrast, typically saw support for learning as central to "what we do", as a fully integrated and universally available component of their taught provision:

“we are a supportive university. It's a supportive environment and therefore it's part of the norm. It's not an overlay or you need to identify so that we know to support you, we support all of our students. So, and I think, actually, it's for some people, obviously not for all, there are always individuals who want to identify themselves as needing the support, but oftentimes they're looking at it as an opportunity to be a normal part of the environment without having a label stuck on ... But we wouldn't sell it from the perspective of “Oh, we've noticed that you're a contextual offer and therefore ... " [LT]

Indeed, locally transformative universities typically saw their central purpose as being to actively foster the as yet unrealised potential in their students:

"you're probably more interested in unfinished work and work that shows a process ... it's not about having people who are fully formed ..." [LT]

“because I would rather have someone who's in it for the long run, who's determined, won't give up, than someone who has more ability but maybe doesn't have to work so hard" [LT]

\section{Discussion}

As is evident from our data, the organisational identities of universities and their corresponding strategies for position-taking in global, national and local higher education fields have deep implications for organisational orientations to admission. Identifying as a globally competitive or, to a lesser but still significant extent, as a nationally selective university is seen to be synonymous with selecting only the 'brightest and best' applicants operationalised principally, if not quite entirely, with reference to high levels of prior academic achievement. Such organisational identities would seem to be fundamentally incompatible with more than the most minimal widening of access given that progressive admissions policies extend only to the comparatively few disadvantaged students who have succeeded academically despite the odds, and who can be expected to "perform just as 
well" as the standard student with no more than the "traditional" amount and type of learning support. Crucially, the disproportionate focus of widening access efforts on undoubtedly impressive but relatively rare instances in which disadvantaged students have overcome structural inequality renders almost invisible the much more common story: that structural inequality impedes the school attainment of disadvantaged students. By engaging with only a small part of the bigger picture, the most esteemed universities are able to sidestep the question of whether the purpose of a university might be to actively support students to learn, as opposed to admitting only those for whom success under their own steam is virtually guaranteed from the outset.

The identities of universities with long histories of recruiting students locally for the purpose of offering a transformative higher education experience are much more compatible with an appreciation of the worth of disadvantaged students whose achievement levels are low compared to the national average but strong relative to those from similar backgrounds. However, the ambitions of some locally transformative universities to maintain or gain a foothold in the national higher education field in relation to particular disciplinary specialisms means that even they are not entirely immune to the pull of grades as a marker of the worth of applicants and, by extension, of the organisation. The continuing valorisation of the national over the local higher education field, coupled with an anticipated increase in the applicant demand for places in the context of restricted supply, presents a challenge to widening access within locally transformative universities too.

Of course, Scottish universities which lay claim, or aspire to lay claim, to the most esteemed organisational identities are not unique in restricting the scope of progressive admissions policies to what might be called the 'heroic disadvantaged'; a similar phenomenon has been observed at elite universities in England and America (Mountford-Zimdars 2016; Boliver 2017). Nor are distinction-seeking Scottish universities unusual in expecting members of marginalised groups to conform to the norm of the dominant group (Maher and Tetreault 2007) or in regarding students that are less well-prepared for university study as a threat to excellence (Ghosh 2012). Organisational identity is likely to represent a barrier to widening access via strongly progressive admissions policies wherever universities compete for places in global and national higher education fields.

Nahai, focusing on the case of Oxford University, refers to this dominant paradigm as "democratic elitism" which "is in fact elitist insofar as it prioritises excellence, even at the expense of social justice" (Nahai 2013, p. 695). Nahai contrasts democratic elitism favourably with "organic conservatism" which historically "defended social privilege and supported explicit class bias in admissions", but also regards the shift to democratic elitism as amounting to little more than "replacing admission by social class with the 'amoral elite' criteria of academic excellence." (Nahai 2013, p. 686). Nahai contrasts both organic conservatism and democratic elitism unfavourably with what she terms the "social democracy" model, in which "[c]ognisant of unequal starting points arising from class privilege", social democrats primarily judged the success of their efforts on the basis of equal outcomes rather than equal procedures" (Nahai 2013, p. 686).

Thomas makes a similar point, pointing to the dominant "deficit model" of widening access discourses in the UK which lead, at best, to initiatives that are "more or less 'bolted on' to core work" (Thomas 2011, pp. 617-18; Jones and Thomas 2005), and contrasting this with a genuinely transformative approach to widening access. As Thomas argues:

“... a transformative approach to access must stress the idea that higher education should be changed to permit it to both gauge and meet the needs of under-represented groups. Rather than being predicated on deficit models of potential entrants and positioning students as lacking aspirations, information or academic preparation, transformation requires serious and far-reaching structural change ... It is also, therefore, concerned with creating an institutional culture that does not require participants to change before they can benefit from higher education." (Thomas 2011, p. 619)

There is undoubtedly a good deal of political will within Scotland currently to achieve a step change in widening access, and for strongly progressive admissions policies to be a major driving force 
in achieving this ambition. The viability of this political vision will depend critically, however, on the willingness of universities, individually and collectively, to engage in identity work which brings the task of selecting for and nurturing as-yet-unrealised potential into the narrative about what constitutes a highly esteemed university. Given the seeming immutability of university organisational identities, and the dominant place occupied by the research-intensive, rather than teaching-focused, 'world-class' university, this may appear to be an impossible task. However, as Nahai has observed:

"Throughout their histories, elite universities have changed their conceptions of what makes applicants meritorious, often explicitly to fulfil political or financial objectives. [ ... ] Carefully engineering eligibility and entry criteria, and applying these systematically, can encourage significant gains for the equity cause ... in a way that maintains academic quality. Such an approach might be called 'outcomes-based meritocracy' for the way it systematically and fundamentally attempts to combine meritocracy and social democracy." (Nahai 2013, p. 696)

There is clearly scope, then, for universities to recognise and redress the implicitly exclusionary nature of their organisational identities given that, as largely autonomous organisations, this kind of identity work is well within their powers. In so doing, universities have the opportunity to lay new claims to esteem, based not on admitting only the 'brightest and best', but also on excellence in supporting disadvantaged learners to achieve their full potential.

Author Contributions: Project design: V.B. and T.M.; Data collection: M.P.; Data analysis: M.P., T.M. and V.B.; Manuscript: V.B., M.P. and T.M.

Funding: This research was funded by the Scottish Funding Council (SFC) as part of its Impact for Access initiative, grant number 0/H15031. The full project report can be found at http:/ / www.sfc.ac.uk/access-inclusion/ contextualised-admissions/evaluating-contextual-admissions.aspx.

Acknowledgments: Thanks go to the SFC for funding this project and for supporting the research team throughout the project period. We are also grateful to the participants in this project for being so generous with their time, and for the clarity and thoughtfulness with which they spoke about their institution's approach to undergraduate admissions.

Conflicts of Interest: The authors declare no conflict of interest.

\section{References}

Albert, Stuart, and David A. Whetten. 1985. Organizational identity. Research in Organizational Behavior 7: 263-95.

Boliver, Vikki. 2015. Are there distinctive clusters of higher and lower status universities in the UK? Oxford Review of Education 41: 608-27. [CrossRef]

Boliver, Vikki. 2017. Misplaced optimism: how higher education reproduces rather than reduces social inequality. British Journal of Sociology of Education 38: 423-32. [CrossRef]

Boliver, Vikki, Mandy Powell, Tiago Moreira, and Stephen Gorard. 2017. Mapping and Evaluating the Use of Contextual Data in Undergraduate Admissions in Scotland. Edinburgh: Scottish Funding Council.

Boliver, Vikki, Stephen Gorard, and Nadia Siddiqui. 2017. How can we widen participation in higher education? The promise of contextualised admissions. In The University as a Critical Institution? Edited by Rosemary Deem and Heather Eggins. Rotterdam: Sense Publishers, pp. 95-110.

Bourdieu, Pierre. 1993. The Field of Cultural Production. Cambridge: Polity Press.

Bourdieu, Pierre. 1996. The State Nobility: Elite Schools in the Field of Power. Translated by L. Clough. Oxford: Polity Press.

Brankovic, Jelena. 2018. The Status Games They Play: Unpacking the Dynamics of Organisational Status Competition in Higher Education. Higher Education 75: 695-709. [CrossRef]

Cree, V.E., Linda Croxford, J. Halliwell, C. Iannelli, L. Kendall, and D. Winterstein. 2006. Widening Participation at an Ancient Scottish University. Scottish Affairs 56: 102-30. [CrossRef]

Croxford, Linda, Gemma Docherty, Rebecca Gaukroger, and Kathleen Hood. 2014. Widening Participation at the University of Edinburgh: Contextual Admissions, Retention, and Degree Outcomes. Scottish Affairs 23: 192-216. [CrossRef] 
Commission on Widening Access. 2015. Interim Report; Edinburgh: Scottish Government.

Commission on Widening Access. 2016. A Blueprint for Fairness. The Final Report of the Commission on Widening Access; Edinburgh: Scottish Government.

David, Matthew. 2016. Fabricated World Class: Global University League Tables, Status Differentiation and Myths of Global Competition Differentiation and Myths of Global Competition. British Journal of Sociology of Education 37: 169-89. [CrossRef]

Ghosh, Ratna. 2012. Diversity and Excellence in Higher Education: Is There a Conflict? Comparative Education Review 56: 349-65. [CrossRef]

Gorard, Stephen, Vikki Boliver, Nadia Siddiqui, and Pallavi Banerjee. 2017. Which are the most suitable contextual indicators for use in widening participation to HE? Research Papers in Education. [CrossRef]

Hazelkorn, Ellen. 2007. The Impact of League Tables and Ranking Systems on Higher Education Decision Making. Higher Education Management and Policy 19: 1-24. [CrossRef]

Blackburn, Lucy Hunter, Gitit Kadar-Satat, Sheila Riddell, and Elisabet Weedon. 2016. Access in Scotland: Access to Higher Education for People from Less Advantaged Backgrounds in Scotland. London: Sutton Trust.

Jones, Robert, and Liz Thomas. 2005. The 2003 UK government higher education white paper: A critical assessment of its implications for the access and widening participation agenda. Journal of Education Policy 20: 615-30. [CrossRef]

Labianca, Giuseppe, James F. Fairbank, James B. Thomas, Dennis A. Gioia, and Elizabeth E. Umphress. 2001. Emulation in Academia: Balancing Structure and Identity. Organization Science 12: 312-30. [CrossRef]

MacDonald, Ginger Phillips. 2013. Theorizing university identity development: multiple perspectives and common goals. Higher Education 65: 153-66. [CrossRef]

Marginson, Simon. 2006. Dynamics of National and Global Competition in Higher Education. Higher Education 52: 1-39. [CrossRef]

Marginson, Simon. 2008. Global Field and Global Imagining: Bourdieu and Worldwide Higher Education. British Journal of Sociology of Education 29: 283-301. [CrossRef]

Mateos-González, José Luis, and Vikki Boliver. forthcoming. Performance-Based University Funding and the Drive towards 'Institutional Meritocracy' in Italy. British Journal of Sociology of Education.

Maher, Frances A., and Mary Kay Thompson Tetreault. 2007. Privilege and Diversity in the Academy. New York: Routledge.

Mountford-Zimdars, Anna. 2016. Meritocracy and the University: Selective Admission in England and the United States. London: Bloomsbury.

Nahai, Rebekah N. 2013. Is meritocracy fair? A qualitative case study of admissions at the University of Oxford. Oxford Review of Education 398: 681-701. [CrossRef]

Naidoo, Rajani. 2004. Fields and Institutional Strategy: Bourdieu on the Relationship between Higher Education, Inequality and Society. British Journal of Sociology of Education 25: 457-71. [CrossRef]

Posselt, Julie Renee, Ozan Jaquette, Rob Bielby, and Michael N. Bastedo. 2012. Access Without Equity: Longitudinal Analyses of Institutional Stratification by Race and Ethnicity, 1972-2004. American Educational Research Journal 49: 1074-1111. [CrossRef]

Puusa, Anu, Matti Kuittinen, and Pekka Kuusela. 2013. Paradoxical Change and Construction of Identity in an Educational Organisation. Education Management, Administration E Leadership 41: 165-78.

Ragin, Charles C. 2014. The Comparative Method: Moving Beyond Qualitative and Quantitative Strategies. California: University of California Press.

SFC. 2018. Scottish Funding Council Report on Widening Access 2016-17. Background Tables. Edinburgh: Scottish Funding Council.

Schwartz, Steven. 2004. Fair Admissions to Higher Education: Recommendations for Good Practice; Nottingham: Department for Education and Skills.

Scottish Government. 2014. One Scotland: The Government's Programme for Scotland 2014-15; Edinburgh: Scottish Government.

Stensaker, Bjørn. 2015. Organisational identity as a concept for understanding university dynamics. Higher Education 69: 103-15. [CrossRef]

Thomas, Liz. 2011. Institutional Transformation to Engage a Diverse Student Body. In Institutional Transformation to Engage a Diverse Student Body. Edited by Liz Thomas and Malcolm Tight. Bingley: Emerald.

UCAS. 2015. End of Cycle Report 2015. December 2015. Cheltenham: UCAS. 
UCAS. 2017. End of Cycle Report 2017: Patterns by Applicant Characteristics. Cheltenham: UCAS.

Universities Scotland. 2017. Working to Widen Access. Edinburgh: Universities Scotland.

Weber, Max. 1949. The Methodology of the Social Sciences. Translated and Edited by Edward A. Shils and Henry A. Glencoe: The Free Press.

Whetten, David A. 2006. Albert \& Whetten Revisited: Strengthening the Concept of Organisational Identity. Journal of Management Inquiry 15: 219-34.

Yin, Robert K. 2009. Case Study Research: Design and Methods (Applied Social Research Methods). London: Sage.

2018 by the authors. Licensee MDPI, Basel, Switzerland. This article is an open access article distributed under the terms and conditions of the Creative Commons Attribution (CC BY) license (http://creativecommons.org/licenses/by/4.0/). 